\title{
Analysis of Modular Inverter-fed Six-Winding Transformers for WECS-Mains Interface
}

\author{
Antonino Di Gerlando, Khaled ElShawarby, Giovanni Maria Foglia, Roberto Perini
}

\begin{abstract}
The paper describes the analysis of Multi-Winding Transformers (MWTs), with inverter fed Low Voltage (LV) primary windings and with secondary windings paralleled to the Medium Voltage (MV) mains. Parallel or series inverter dc link connections can be used. Typical application fields are medium power Wind Energy Conversion Systems (WECSs), using modular components (multi-module generator and transformer). Design and modeling aspects of a Six-Winding Transformer (6WT) are investigated: arrangement of coils around the column; coils positioning in the window, FEM parameter identification. Then, the transformer performances are studied, considering inverter command parameters, sharing and waveform distortion of transformer and mains currents.
\end{abstract}

Index Terms - multi-winding transformers, transformer design, transformer model, inverter fed transformer operation.

\section{INTRODUCTION}

$\mathrm{T}^{\mathrm{s}}$ he growing dissemination of WECSs for on- and offshore plants brought to several machine solutions: DFIGs or PM generators $[1,2]$, with radial or axial flux disposition [3], geared or direct drive layout [4], full or slip power electronic conversion units [5], multi-phase machines [6, 7], multi-module systems [8]. Also the conversion chain may have many different dispositions $[9,10]$.

To connect the onshore and offshore wind farms to electric power system, various series/parallel and AC/DC configurations, and high-voltage AC and DC (HVAC and HVDC) transmission systems have been developed [11].

Among these, multi-phase machines and multi-module systems are investigated for several advantages:

- increasing the conversion chain efficiency;

- ensuring a good operation waveform quality;

- splitting the turbine power, in order to limit the single module rating and to increase the system reliability.

As for the generator-side subsystem, one of the possible solutions is a modular PM axial flux generator, with several stator modules $[12,13]$; the following advantages exist:

- limitation of module voltage and current rating;

- magnetic decoupling among three-phase modules;

- possible Sequential Command of the modular inverters (i.e.: shifted carrier signals of the neighboring PWM converters); - use of standard IGBTs and off the shelf two-level inverters.

As concerns the dc link voltage level, the following two situations can be considered (Fig.1, referred to 3 modules): -in case of on-shore plants, in which a back-to-back

A. Di Gerlando, G. Foglia and R. Perini are with Dpt. of Energy, Politecnico di Milano, via La Masa 34, 20156 Milano - Italy [antonino.digerlando, gianmaria.foglia, roberto.perini] @polimi.it

K. Elshawarby is with Schlumberger Limited, 13 Brunel Way, GL103SX Stonehouse - United Kingdom, kelshawarby2@slb.com disposition is typical, all the inverters can be connected in parallel on a LV dc side, because the high dc current level can be accepted in short length connections (Fig. 1a);

- in off-shore plants, the extended dc line length requires a MV dc voltage, in order to limit the dc line current sizing: this requires inverters with dc side series connection, both at the generator side and at the mains side, together with a suited control of the module dc partial voltages (Fig. 1b).

For grid connection, a Multi-Winding Transformer (MWT) can be used. This paper will focus on the design of a Six Winding Transformer (6WT) with Sequential Command.

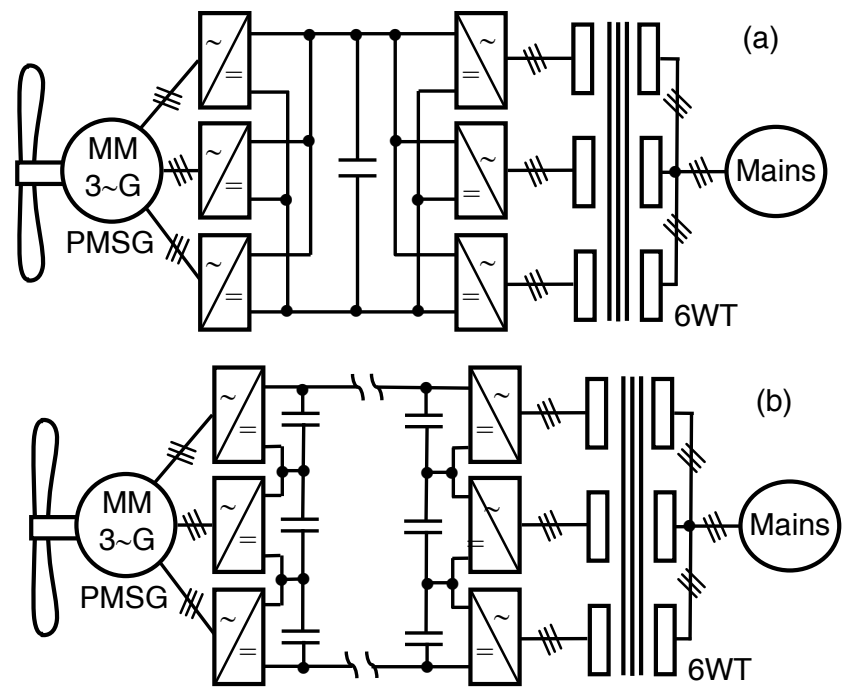

Fig. 1. Scheme of a multi-module WECS with 3 modules: a three-phase threemodule PM synchronous generator; three generator-side converters and three mains-side inverters; a Multi-Winding three-phase Transformer (MWT), with six windings/column (Six-Winding Transformer: 6WT):

a) inverters paralleled on a LV dc link (for on-shore plants);

b) inverters series connected on a MV dc link (for off-shore plants).

These solutions have the following benefits:

- power sharing among equal two-level standard inverters;

- possibility to segregate a faulted system portion, ensuring the system operation continuity, even at reduced power;

- superposition of the shifted primary current ripples, with lower distortion of the total current delivered to the mains thanks to the Sequential Command.

In principle, assuming equal power rating, the two 6WTs in Fig. $1 \mathrm{a}$ and $1 \mathrm{~b}$ could be the same, in terms of core and copper sizing and winding data, supposing that each partial dc voltage of Fig. 1b is the same of the dc voltage in Fig. 1a: however, a significant difference could follow from the need to increase some insulation distances in the 6WT of Fig. 1b, due to the primary windings dc voltage offsets caused by the series connection of the inverters at the dc side. 
In [14] another three-phase MWT has been studied, with four windings per column and concentric disposition: three inverter-fed LV windings, one MV winding connected to the mains. This topology has the following features:

- the currents sharing and waveforms are fair;

- in case of a partial fault in the primary side, excluding the corresponding winding allows an acceptable operation: in fact, the other windings ensure a correct local MMF balance;

-however, some issues arise in case of displaced inverter carrier signals, that in principle should reduce the current distortion: in fact, the low leakage inductances among primary windings cause high primary current ripples, due to the instantaneous differences among inverter voltages [14].

In order to increase the leakage inductance, overcoming this issue, in this paper a different MWT disposition is studied: $N_{m}$ winding modules are axially stacked around each column (here $N_{m}=3$ ); each winding module includes a LV Primary Winding (PW), radially faced to a MV Secondary Winding (SW), see Fig. 2 and the SWs are paralleled to the mains, see Fig. 1.

This secondary side splitting is aimed to always ensure a correct operation even if a partial fault occurs. In fact, in case one primary winding should be excluded, a unique secondary winding would imply a local MMF unbalance, with strong leakage field distortion, high radial flux density components, strong local losses increase and heating; on the contrary, the secondary winding splitting allows a correct module exclusion.

In this paper, the case of Fig 1a is investigated (the SWs are paralleled to the mains). The design data of a $6 \mathrm{WT}$ are given, its model is developed, and the components and system performances are evaluated, in particular 6WT currents, waveform quality of the mains resultant currents, voltage waveform at the dc link side. One important aspect will be analyzed, concerning the balance of the 6WT currents (same amplitude and phase). The inverter current control can ensure the current balance either at the PW or at the SW terminals: if the SW currents are balanced by the inverters control, this can avoid excess losses in the SWs, but does not prevent the PW current unbalance, which is an issue both for the PW losses and heating, but mainly for the inverters loading, that would be unbalanced too. So, it is preferable to balance the PW currents by the inverter current control. In order to balance also the SW currents, a suited winding layout will be studied.

The paper is organized as follows: Section II reports 6WT sizing criteria and data of a design example; Section III describes the 6WT AC model, its parameter identification and the inverter feeding conditions to ensure the PW current balance; Section IV analyzes the SW currents unbalance; Section V presents a model suited to transient analysis; Section VI shows some 3D FEM validation results; Section VII presents concluding remarks and future developments.

\section{TRANSFORMER DESIGN CRITERIA AND MAIN DATA}

The analysis refers to a three-phase 6WT: each column has three axially stacked couples of concentric windings (Fig.2). Thus, the three-phase $6 \mathrm{WT}$ can be thought as made by $\mathrm{N}_{\mathrm{m}}=3$ axially stacked modules. Even if the $6 \mathrm{WT}$ is equivalent to 3 two-winding three-phase transformers, the $6 \mathrm{WT}$ is more compact.

Each of the PWs is fed by one inverter (Fig.1).

Fig. 2 shows the main sizes: the LV PWs Pk are external, while the MV SWs Sk are close to the column $(\mathrm{k}=1,2,3)$.

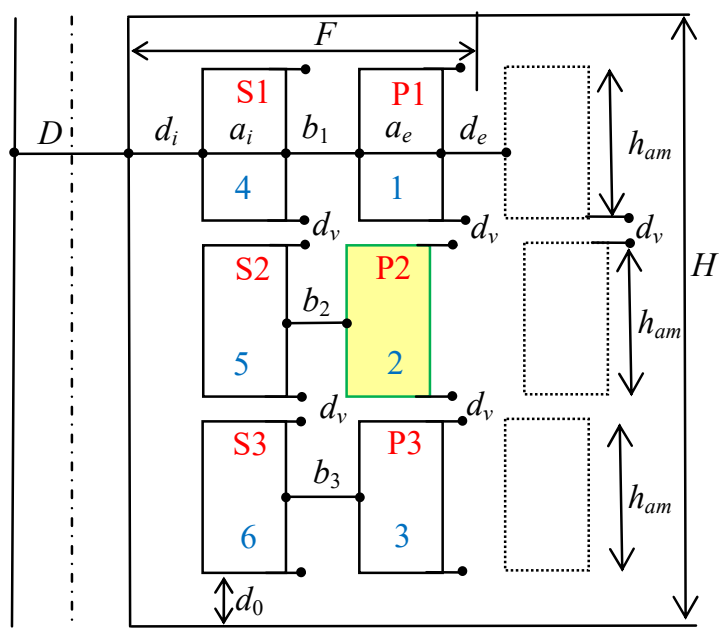

Fig. 2. Cross section of one core column of the 6WT, with LV PWs (P1, P2, P3) and MV SWs (S1, S2, S3); axial disposition of winding couples; the main design sizes are shown, together with the generic coil numbers $(1,2,3,4,5,6)$

TABLE I

MAIN SIX WINDING TRANSFORMER RATED AND CONSTRUCTIONAL DATA (SIZES IN [mm])

Rated voltages; frequency: $V_{L V}=0.69 \mathrm{kV} ; V_{H V}=20 \mathrm{kV} ; f_{n}=50 \mathrm{~Hz}$

Rated currents; Power Factor: $I_{p h L V}=880.8 \mathrm{~A}_{\mathrm{rms}} ; I_{p h H V}=30.4 \mathrm{~A}_{\mathrm{rms}} ; P F=0.9$

Rated active powers: $\quad P_{P 1}=P_{P 2}=P_{P 3}=P_{S I}=P_{S 2}=P_{S 3}=1 \mathrm{MW}$

Rated loadings, turn EMF: $\quad B=1.74 \mathrm{~T} ; \quad S=3 \mathrm{~A} / \mathrm{mm}^{2} ; \quad E_{\text {turn }}=19.5 \mathrm{~V}_{\text {rms }}$

Connection; LV, HV number of turns: Yy; $N_{L V}=20, \quad N_{H V}=579$

Axial and radial sizes: $d_{0}=50 ; d_{v}=50 ; d_{i}=36 ; d_{e}=26 ; b_{1}=b_{3}=135 ; b_{2}$ t.b.d.

Column $D$, windings width and height: $D=306 ; a_{i}=76.8 ; a_{e}=16.2 ; h_{a m}=218$

$\mathrm{LV}$ winding helix disposition; $N_{p p}=1$ parallel path;

data: $\quad N_{p c}=6$ plates/conductor; plate sizes: $10 \times 5$

HV winding disk disposition, with $N_{D}=19$ disks; conductor consisting

data: $\quad$ of $N_{p c H V}=1$ plate/conductor; plate sizes: $5 \times 2.12$

number of steps of the column: $8 ; \quad \mathrm{Fe}, \mathrm{Cu}$ masses [kg]: 3130, 1880

Core lamination material: JFE STEEL 50JN400

Each module sizing criteria are similar to those used for two-winding concentric transformers, with some peculiarities:

- the radial inter-coil spaces should be wider than the insulation distances, to increase leakage reactance (0.15-0.20 $\mathrm{pu})$, limiting the inverter current ripples and avoiding or reducing output power filters; thus, $H / F$ ratio is low $(\sim 3)$;

- of course, wider radial distance implies higher copper mass and losses, (even if these drawbacks are compensated by the absence or reduction of output filters);

- all the PWs and SWs have the same global sizes $\left(a_{e}, h_{a m}\right.$ and $a_{i}, h_{a m}$ respectively); moreover, the winding data are the same for all PWs and for all SWs;

- once defined rated power and voltages, the rated currents are known: the copper losses can be limited by ensuring low resistance values, hence a low number of turns: this implies a high core cross section and a high turn EMF;

- conversely, a low number of turns implies low inductances and high core mass and losses; 
- the inter-coil distances $b_{k}$ should have the same values for winding modules symmetrically disposed with respect to the column middle axial position: in Fig. 2, it means $b_{1}=b_{3}$; as concerns $b_{2}$ (and the position of $\mathrm{P} 2$ winding, highlighted in Fig. 2), its choice will be analyzed later.

Applying all these criteria leads to the data of Table I.

\section{TRANSFORMER AC MODEL, PARAMETER IDENTIFICATION}

As reported in the classical theory [15], accurate singlephase transformer equivalent circuits have been developed for four windings/column (Starr, 1933) and for five windings/column (Aicher, Johnson, 1943). For transformers with higher number of windings/columns, recently some models have been proposed [16-19]; however, in general their use is cumbersome and their accuracy not always adequate for the analysis here considered. Thus, in order to develop the 6WT model, an approach based on self and mutual impedances will be used: the advantages in adopting this method are simplicity of use and accuracy of results.

In the following, a single column model is adopted, thus all the quantities belong to the same phase (for instance, phase A). All the quantities will be referred to the PW side (LV).

Let the following vectors of phasor fundamental PW and SW voltages and currents (phases a, A) be defined (each vector has 3 elements, according to $\mathrm{N}_{\mathrm{m}}=3$ modules):

$$
\begin{array}{ll}
\overline{\boldsymbol{V}}_{\boldsymbol{P}}=\left[\begin{array}{llll}
\bar{V}_{P 1} & \bar{V}_{P 2} & \bar{V}_{P 3}
\end{array}\right]^{\mathrm{T}}, & \overline{\boldsymbol{V}}_{\boldsymbol{S}}=\left[\begin{array}{lll}
\bar{V}_{S 1} & \bar{V}_{S 2} & \bar{V}_{S 3}
\end{array}\right]^{\mathrm{T}} \\
\overline{\boldsymbol{I}}_{\boldsymbol{P}}=\left[\begin{array}{llll}
\bar{I}_{P 1} & \bar{I}_{P 2} & \bar{I}_{P 3}
\end{array}\right]^{\mathrm{T}}, & \overline{\boldsymbol{I}}_{S}=\left[\begin{array}{llll}
\bar{I}_{S 1} & \bar{I}_{S 2} & \bar{I}_{S 3}
\end{array}\right]^{\mathrm{T}}
\end{array}
$$

The relation among these vectors can be expressed by introducing an impedance matrix $\overline{\boldsymbol{Z}}$ (here with order $6 \times 6$ ), which can be divided into four sub-matrices as:

$$
\left[\begin{array}{l}
\bar{V}_{P} \\
\bar{V}_{S}
\end{array}\right]=\bar{Z} \cdot\left[\begin{array}{l}
\bar{I}_{P} \\
\bar{I}_{S}
\end{array}\right]=\left[\begin{array}{ll}
\bar{Z}_{P P} & \bar{Z}_{P S} \\
\bar{Z}_{S P} & \bar{Z}_{S S}
\end{array}\right] \cdot\left[\begin{array}{c}
\bar{I}_{P} \\
\bar{I}_{S}
\end{array}\right]
$$

By expressing $\overline{\boldsymbol{V}}_{\boldsymbol{P}}$ as a function of $\overline{\boldsymbol{I}}_{\boldsymbol{P}}$ and $\overline{\boldsymbol{V}}_{\boldsymbol{S}}$, it follows:

$$
\bar{V}_{P}=\left(\bar{Z}_{P P}-\bar{Z}_{P S} \cdot \bar{Z}_{S S}^{-1} \cdot \bar{Z}_{S P}\right) \cdot \bar{I}_{P}+\bar{Z}_{P S} \cdot \bar{Z}_{S S}^{-1} \cdot \bar{V}_{S} .
$$

Let $\bar{V}_{\text {grid }}=V_{\text {grid }}$ be the rated rms grid voltage, and $\bar{I}_{i n v}$ be the rms fundamental inverter current (i.e. PW current, with amplitude and phase of any generic operating condition).

Thanks to the SW mains parallel connection, it follows:

$$
\overline{\boldsymbol{V}}_{S}=\left[\begin{array}{lll}
\bar{V}_{S 1} & \bar{V}_{S 2} \bar{V}_{S 3}
\end{array}\right]^{\mathrm{T}}=\left[\begin{array}{lll}
1 & 1 & 1
\end{array}\right]^{\mathrm{T}} \cdot V_{\text {grid }}
$$

Moreover, the control system is supposed to be able to maintain all the PW currents equal among them; thus:

$$
\overline{\boldsymbol{I}}_{\boldsymbol{P}}=\left[\begin{array}{lll}
\bar{I}_{P 1} & \bar{I}_{P 2} & \bar{I}_{P 3}
\end{array}\right]^{\mathrm{T}}=\left[\begin{array}{lll}
1 & 1 & 1
\end{array}\right]^{\mathrm{T}} \cdot \bar{I}_{i n v}
$$

Once (4) and (5) are substituted in (3), we obtain the PW voltages $\bar{V}_{P k}{ }^{*}(\mathrm{k}=1,2,3)$ which ensure that (5) holds: $\bar{V}_{P k}{ }^{*}$ values become the references for the inverters.

Again from (2), $\overline{\boldsymbol{I}}_{\boldsymbol{S}}$ is expressed as a function of $\overline{\boldsymbol{I}}_{\boldsymbol{P}}$ and $\overline{\boldsymbol{V}}_{\boldsymbol{S}}$ :

$$
\bar{I}_{S}=\bar{Z}_{S S}^{-1} \cdot \bar{V}_{S}-\bar{Z}_{S S}^{-1} \cdot \bar{Z}_{S P} \cdot \bar{I}_{P} .
$$

Considering (4) and (5), it gives:

$$
\left[\begin{array}{l}
\bar{I}_{S 1} \\
\bar{I}_{S 2} \\
\bar{I}_{S 3}
\end{array}\right]=\overline{\boldsymbol{Z}}_{\boldsymbol{S S}}^{-1} \cdot\left[\begin{array}{l}
1 \\
1 \\
1
\end{array}\right] \cdot V_{\text {grid }}-\overline{\boldsymbol{Z}}_{\boldsymbol{S S}}^{-1} \cdot \overline{\boldsymbol{Z}}_{\boldsymbol{S P}} \cdot\left[\begin{array}{l}
1 \\
1 \\
1
\end{array}\right] \cdot \bar{I}_{i n v} \quad .
$$

As regards the matrix $\overline{\boldsymbol{Z}}$, it can be written as:

$$
\overline{\boldsymbol{Z}}=\boldsymbol{R}+\mathrm{j} \cdot \omega \cdot \boldsymbol{L},
$$

with $\omega$ the mains angular frequency, $\boldsymbol{L}$ the $6 \times 6$ self and mutual inductance matrix, $\boldsymbol{R}$ the equivalent resistance matrix; in (8) all the parameters are referred to the PW side.

No closed-form analytical approach can be used for the calculation of $\boldsymbol{L}$ elements, because of the complicated field map layout (see an example in Fig. 3a); they can be estimated by FEM: a 2DRZ Magneto Static (MS) simulation can be used, without the need to model in detail the windings structure (actual conductors, with transposed plates). The 2DRZ MS model corresponds to Fig. 2: just one limb is considered; thanks to the RZ FEM approach, just one-half limb is modeled. An attention should be given when designing the yoke, since in an RZ simulation the yoke is a cup, which is very different from the yoke of a core type transformer. To get correct results, the closing limb height and the yoke length are increased, with an ideal closing path $\left(\mu_{\text {ideal }}=10^{6} \cdot \mu_{0}\right)$; moreover, a limb portion equal to the original limb height is set, with a sound permeability $\left(\mu_{\text {limb }}=2000 \cdot \mu_{0}\right)$ : this ensures a correct magnetizing permeance. Some further 3D MS simulations of a single phase 6WT have been used to validate the 2DRZ approach. The two FEM models (Maxwell Ansys [20]) are shown in Fig. 3 (a) and (b) respectively.

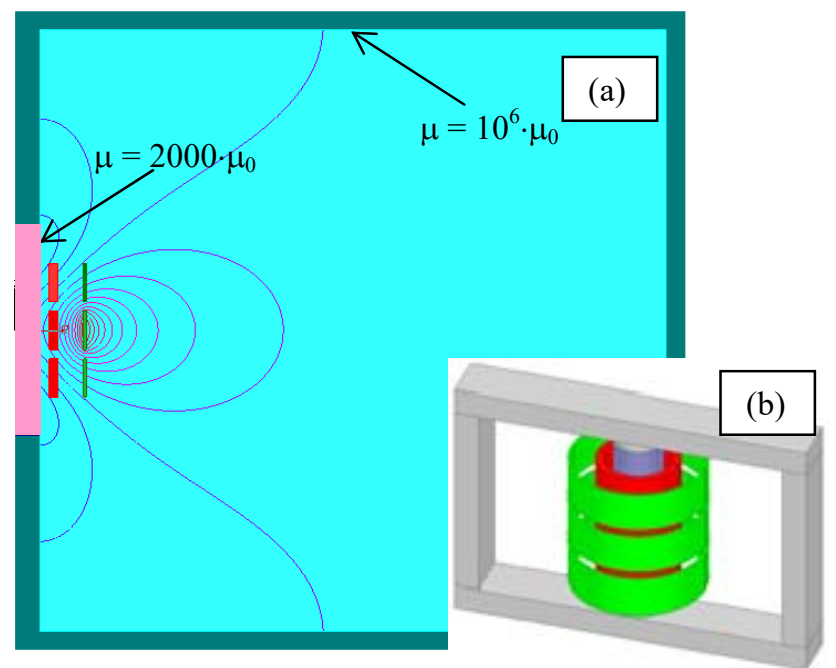

Fig. 3. (a): Layout of the FEM 2DRZ model, for inductance matrix calculation (the leakage field map refers to the condition in which just P2 winding is fed). (b): 3D FEM model of a single phase $6 \mathrm{WT}$.

The $\boldsymbol{L}$ parameters obtained by the 3D model (Fig. 3b) differ by $1-2 \%$ with respect to those obtained by the $2 \mathrm{DRZ}$ model (Fig. 3a): this difference is mainly due to the different closing path of the magnetic circuit, which affects the magnetizing permeance. However, the field in air, which mainly affects the current sharing among the windings, remains almost unchanged, because the winding layout is unvaried: as a 
consequence, the phasor results by (3) and (7), for 3D and for 2DRZ models, are very similar (differences well below $1 \%$ ).

As concerns $\boldsymbol{R}$, it includes the winding ohmic resistances, but also the additional resistances, due to the eddy current losses induced in all the windings by the leakage field. As a consequence, some additional resistances should exist also outside the $\boldsymbol{R}$ main diagonal. Actually, these additional resistances are very low, due to both the balanced current condition and the vertical stacked disposition of the winding couples. Thus, $\boldsymbol{R}$ can be assumed as diagonal:

$$
\boldsymbol{R}=\operatorname{diag}\left(r_{1 P} \cdot k_{a 1 P}, r_{2 P} \cdot k_{a 2 P}, r_{3 P} \cdot k_{a 3 P}, r_{1 S} k_{a 1 S}, r_{2 S} k_{a 2 S}, r_{3 S^{*}} k_{a 3 S}\right),(9)
$$

where $r_{k P}$ and $r_{k S}$ are ohmic resistances and $k_{a k P}, k_{a k s}$ are the well-known classical additional loss coefficients $(k=1,2,3)$.

Once obtained the $\boldsymbol{Z}$ matrix, voltage and current phasors at the 6WT terminals are obtained, by (3) and (7).

\section{SECONDARY WINDING CURRENT BALANCING}

With the conditions of Section III, by assuming (4)-(5), by using the design sizes of Table I, and with $b_{1}=b_{2}=b_{3}$, the secondary currents (6) are unbalanced. On the contrary, in order to have the best current operating conditions of the inverters and of $6 \mathrm{WT}$, the currents $\bar{I}_{S 1}, \bar{I}_{S 2}, \bar{I}_{S 3}$ have to be balanced (same amplitude and phase displacement).

Eq. (7) shows that the SW current phasors depend on the sub-matrix impedances $\overline{\boldsymbol{Z}}_{S S}{ }^{-1}$ and $\overline{\boldsymbol{Z}}_{\boldsymbol{S S}}{ }^{-1} \cdot \overline{\boldsymbol{Z}}_{\boldsymbol{S P}}$ : clearly, these impedances depend on the geometrical sizes and position of the windings. These elements should be analyzed, in order to obtain the $\bar{Z}$ structure suited to balance the SW currents.

As observed, no analytical relations exist among geometrical sizes and $\boldsymbol{L}$ parameters. The following remarks hold:

- as known, in high rating transformers, inductive phenomena prevail on resistive ones, in particular for current sharing;

-the current balance mainly depends on the leakage parameters embedded in $\boldsymbol{L}$ : this behavior is similar to what occurs in transformers connected in parallel, in which the current sharing depends on the leakage inductances;

-the 6x6 inductance matrix $\boldsymbol{L}$ of the $6 \mathrm{WT}$ shows that all the self and mutual parameters are highly coupled among them; however, like in two-winding transformers, also in 6WT it can be verified that the $k^{\text {th }}$ module leakage path is mainly affected by its own inter-coil distance $b_{k}$;

- thus, the current balance can be improved mainly by modulating the inter-coil distances $b_{k}$;

- different choices could be made; the simplest is keeping unvaried $b_{1}=b_{3}$, and modifying the inter-coil distance $b_{2}$ in order to maintain constructional symmetry;

- supposing that $b_{2}$ is to be reduced, it is better to reduce P2 radius rather than increase $\mathrm{S} 2$ radius, to limit copper losses.

A confirmation of these considerations, concerning the change of $b_{2}$, can be obtained by approximating (7) by just inductive terms, as typical in high rating transformers:

$$
\left[\begin{array}{l}
\bar{I}_{S 1} \\
\bar{I}_{S 2} \\
\bar{I}_{S 3}
\end{array}\right] \approx \frac{1}{\omega} \cdot \boldsymbol{L}_{\boldsymbol{S S}}^{-1} \cdot\left[\begin{array}{l}
1 \\
1 \\
1
\end{array}\right] \cdot V_{\text {grid }}-\boldsymbol{L}_{\boldsymbol{S S}}^{-1} \cdot \boldsymbol{L}_{\boldsymbol{S P}} \cdot\left[\begin{array}{l}
1 \\
1 \\
1
\end{array}\right] \cdot \bar{I}_{i n v}
$$

The first addend in (10) is negligible compared with the second one due to the division by $\omega$. Thus, (10) becomes:

$$
\left[\begin{array}{l}
\bar{I}_{S 1} \\
\bar{I}_{S 2} \\
\bar{I}_{S 3}
\end{array}\right] \approx-\boldsymbol{L}_{\boldsymbol{S S}}^{-1} \cdot \boldsymbol{L}_{\boldsymbol{S P}} \cdot\left[\begin{array}{l}
1 \\
1 \\
1
\end{array}\right] \cdot \bar{I}_{i n v} \cdot
$$

Due to the transformer constructional symmetry, some self and mutual inductances of the $\boldsymbol{L}$ matrix are the same (subscripts 1, ..6 correspond to the winding numbering in Fig. 2), such as:

$$
\begin{gathered}
L_{11}=L_{33}, L_{44}=L_{66}, L_{14}=L_{36}, L_{34}=L_{16}, \\
L_{15}=L_{35}, L_{24}=L_{26}, L_{45}=L_{56} .
\end{gathered}
$$

Therefore, (11) can be rewritten as:

$$
\left[\begin{array}{c}
\bar{I}_{S 1} \\
\bar{I}_{S 2} \\
\bar{I}_{S 3}
\end{array}\right] \approx \frac{\bar{I}_{i n v}}{\left|L_{S S}\right|} \cdot\left[\begin{array}{c}
L_{55} \cdot\left(L_{14}+L_{16}+L_{24}\right)-L_{45} \cdot\left(2 L_{15}+L_{25}\right) \\
-2 L_{45} \cdot\left(L_{14}+L_{16}+L_{24}\right)+\left(L_{44}+L_{46}\right) \cdot\left(2 L_{15}+L_{25}\right) \\
L_{55} \cdot\left(L_{14}+L_{16}+L_{24}\right)-L_{45} \cdot\left(2 L_{15}+L_{25}\right)
\end{array}\right] .
$$

Some remarks can be deduced from the structure of (12):

- $\bar{I}_{S 1}, \bar{I}_{S 3}$ are always equal, thanks to the constructional symmetry of the windings at the axial ends of the column;

- conversely, in general $\bar{I}_{S 2}$ does not have the same amplitude as $\bar{I}_{S 1}=\bar{I}_{S 3}$. This is due to the interaction between mutual inductances of the middle windings $(\mathrm{P} 2, \mathrm{~S} 2)$ with respect to the rest of the windings.

A way to balance out the three secondary currents is to change the distance $b_{2}$. This leads to the change of the self-inductance of the P2 winding and the mutual inductances between the P2 winding and the other windings.

An unbalance coefficient $k_{u n}$ can be introduced. In case of SW currents balance, $k_{u n}=0$. For the $6 \mathrm{WT}, k_{u n}$ is given by:

$$
\begin{aligned}
& k_{u n}=\bar{I}_{\boldsymbol{S} 2} / \bar{I}_{\boldsymbol{S} 1}-1=I_{\boldsymbol{S} 2} / I_{\boldsymbol{S} 1}-1=I_{\boldsymbol{S} 2} / I_{\boldsymbol{S} 3}-1= \\
& =\frac{-2 L_{45}\left(L_{14}+L_{16}+L_{24}\right)+\left(L_{44}+L_{46}\right)\left(2 L_{15}+L_{25}\right)}{L_{55}\left(L_{14}+L_{16}+L_{24}\right)-L_{45}\left(2 L_{15}+L_{25}\right)}-1
\end{aligned}
$$

Once established that $b_{2}$ is the key parameter in SW currents balancing, a few 2DRZ FEM simulations have been performed, to calculate the $\boldsymbol{L}$ matrices for different $b_{2}$ values.

At first the distances $b_{1}, b_{2}, b_{3}$ are all set to a common value $b_{\text {base }}=135 \mathrm{~mm}$, chosen in such a way to obtain a single module short circuit reactance equal to $0.15-0.20$ p.u..

The FEM calculated inductance matrix $\boldsymbol{L}$ is reported in (14).

$$
\begin{gathered}
\boldsymbol{L}= \\
{[\mathrm{mH}]}
\end{gathered}\left(\begin{array}{ccccccc}
51.5800 & 51.2092 & 51.0317 & 51.2972 & 51.1195 & 50.9619 \\
51.2092 & 51.4920 & 51.2092 & 51.1217 & 51.2070 & 51.1217 \\
51.0317 & 51.2092 & 51.5800 & 50.9619 & 51.1195 & 51.2972 \\
51.2972 & 51.1217 & 50.9619 & 51.4120 & 51.1009 & 50.9035 \\
51.1195 & 51.2070 & 51.1195 & 51.1009 & 51.3200 & 51.1009 \\
50.9619 & 51.1217 & 51.2972 & 50.9035 & 51.1009 & 51.4120
\end{array}\right)
$$

It is apparent that the inductance values are very close among them. The following remarks follow:

- the $\boldsymbol{L}$ values similarity depends on the prevailing role of the magnetizing permeance, common to all the windings;

- the leakage permeances, which mainly affect the current sharing, correspond to the field in air which is reflected in 
the minor differences among the $\boldsymbol{L}$ parameters amplitudes; - a correct estimation of the SW current sharing by (7) requires a very accurate calculation of the inductances in $\boldsymbol{L}$; thus, the FEM convergence condition must be very tight.

Subsequently, further simulations have been performed for other $b_{2}$ values. Once calculated $\boldsymbol{R}$ by (9), by (3) and (7) the SW currents are calculated, at rated conditions, for the chosen $b_{2}$ values. Table II shows the unbalance coefficient $k_{u n}$ (13), the pu SW currents (7), the unbalance $\Delta I_{s}=I_{s 1}-I_{s 2}$ and the pu 6WT copper losses (referred to the losses with $b_{2}=b_{\text {base }}$ ), as a function of $b_{2}$; Fig. 4 shows the $\Delta I_{s}\left(b_{2}\right)$ curve.

TABLE II

UNBALANCE COEFFICIENT $k_{u n}$, pu SW CURRENTS SHARING, UNBALANCE $\Delta I_{s}$ $=I_{s 1}-I_{s 2}$, AND CU LOSSES, AS A FUNCTION OF THE DISTANCE $b_{2}$, FROM (3), (7), (9) (INDUCTIVE PARAMETERS IN (7) ARE BASED ON FEM SIMULATIONS)

\begin{tabular}{cccccc}
\hline \hline $\begin{array}{c}b_{2} \\
{[\mathrm{~mm}]}\end{array}$ & $\begin{array}{c}k_{u n} \\
{[\%]}\end{array}$ & $\begin{array}{c}I_{s 1}=I_{s 3} \\
{[\mathrm{pu}]}\end{array}$ & $\begin{array}{c}I_{s 2} \\
{[\mathrm{pu}]}\end{array}$ & $\begin{array}{c}\Delta I_{s} \\
{[\mathrm{pu}]}\end{array}$ & $\begin{array}{c}\text { Cu Losses } \\
{[\mathrm{pu}]}\end{array}$ \\
\hline $135=b_{\text {base }}$ & 20.36 & 1.067 & 0.852 & 0.215 & 1.000 \\
110 & 2.56 & 1.003 & 0.981 & 0.022 & 0.986 \\
$\mathbf{1 0 7}$ & $\mathbf{0 . 3 1}$ & $\mathbf{0 . 9 9 7}$ & $\mathbf{0 . 9 9 6}$ & $\mathbf{0 . 0 0 1}$ & $\mathbf{0 . 9 8 5}$ \\
100 & -2.56 & 0.974 & 1.038 & -0.064 & 0.982 \\
90 & -14.02 & 0.950 & 1.087 & -0.137 & 0.972 \\
\hline \hline
\end{tabular}

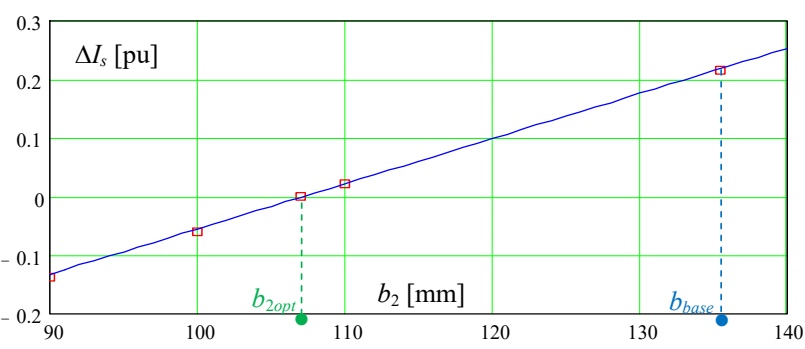

Fig.4. SW current unbalance $\Delta I_{s}=I_{s 1}-I_{s 2}$ [pu] as a function of the distance $b_{2}$ $[\mathrm{mm}]: \square=$ points of Table II; $\longrightarrow=$ linear fitting of the points.

The following remarks can be made:

- as anticipated from (12), the SW currents sharing for $b_{1}=b_{2}=$ $b_{3}=b_{\text {base }}=135 \mathrm{~mm}$ is significantly unbalanced;

- for $b_{2}=b_{\text {base }}, I_{s 2}$ is lower compared with $I_{s 1}=I_{s 3}$; if $b_{2}$ decreases, $I_{s 2}$ increases: this behavior can be explained by the decreased leakage permeance between PW2 and SW2 when $b_{2}$ decreases, thus changing the sharing among the SW currents in favor of $I_{s 2}$;

- the pu $\mathrm{Cu}$ losses decrease when $b_{2}$ decreases, mainly thanks to the reduction of the $\mathrm{P} 2$ winding radius;

- the link between the current unbalance and the distance $b_{2}$ appears linear; thus, the balanced condition can be easily found: it occurs for $b_{2 o p t}=107 \mathrm{~mm}$. For $b_{2}=b_{2 o p t}$, the SW currents are the same $(0.996 \mathrm{pu})$, slightly lower than the PW currents (equal to $1 \mathrm{pu}$, thanks to (5)), because of the magnetizing current, not delivered at the SW terminals;

- some sensitivity analyses have shown that the value of $b_{2 o p t}$ depends on the chosen base value $b_{\text {base }}=b_{1}=b_{2}=b_{3}$;

-in the studied case, the change of $b_{2}$ is rather high in percentage (about $-20 \%$, from $b_{\text {base }}=135 \mathrm{~mm}$ to $b_{2 o p t}=107$ $\mathrm{mm}$ ); this result is not general, because it depends on the system rating and on the starting $b_{\text {base }}$ value;
- for medium-high module rating, the $b_{2}$ change is usually well above the constructional tolerances: thus, the optimal $b_{2}$ value can be adopted without problems;

- to identify $b_{2 o p t}$, the procedure is very simple because, thanks to the linear link between $\Delta I_{s}$ and $b_{2}$, only two Magneto Static (MS) FEM simulations are needed.

\section{TRANSIENT TRANSFORMER MODEL}

Up to now, the 6WT performances have been evaluated in terms of phasors by means of the analytical model (1)-(8).

In order to consider the inverters supply, the overall threephase transformer is modeled by its voltage laws, written in terms of Park variables in time domain:

$$
d \boldsymbol{i}_{\text {Park }} / d t=-\boldsymbol{L}^{-1} \cdot \boldsymbol{R} \cdot \boldsymbol{i}_{\text {Park }}+\boldsymbol{L}^{-1} \cdot \boldsymbol{v}_{\text {Park }}
$$

where the matrices $\boldsymbol{L}, \boldsymbol{R}$ are the previously calculated ones, the input is the vector $\boldsymbol{v}_{\text {Park }}$ of the Park instantaneous voltages at the terminals of the $2 \cdot N_{m}$ windings, the output is the vector $\boldsymbol{i}_{\text {Park }}$ of the corresponding Park instantaneous currents.

The SW voltages are sinusoidal, set by the grid, while the PW voltages follow from a sinusoidal PWM inverter modulation, with fundamental frequency $f_{1}=50 \mathrm{~Hz}$, frequency modulation ratio $m_{f}$ (in the following, $m_{f}=33$ ) and dc voltage, feeding each inverter, equal to $V_{d c 1}=1470 \mathrm{~V}$.

The amplitudes and phases of the inverter control signals correspond to the reference values $\bar{V}_{P k}{ }^{*}$ obtained by (3), on the basis of (4) and (5) (which allow equal PW currents). The carrier signals could be in phase or shifted, to reduce the mains resultant currents distortion (Sequential Command).

Equation (15) is integrated numerically, implemented in MathCad [21], till the achievement of periodic operation.

Table III reports some results, corresponding to the optimized disposition of windings $\left(b_{1}=b_{3}=135 \mathrm{~mm} ; b_{2}=107\right.$ $\mathrm{mm})$ and inverter carrier signals displaced among them by $120^{\circ}$ of the carrier period (that achieves the lowest distortion of the total current delivered to the mains [13]).

TABLE III

PU FUNDAMENTAL VOLTAGES AND CURRENTS, AND CURRENT THD VALUES FOR A SYSTEM WITH: $b_{1}=b_{3}=b_{\text {base }}=135 \mathrm{~mm}, b_{2}=b_{2 o p t}=107 \mathrm{~mm}$ AND INVERTER CARRIER SIGNALS DISPLACED BY $120^{\circ}$ :

THD OF THE RESULTANT SECONDARY CURRENT: THD $_{\text {IStot }}[\%]=1.115$

\begin{tabular}{ccccccc}
\hline \hline winding & $1 \mathrm{P}$ & $2 \mathrm{P}$ & $3 \mathrm{P}$ & $1 \mathrm{~S}$ & $2 \mathrm{~S}$ & $3 \mathrm{~S}$ \\
\hline$V[\mathrm{pu}]$ & 1.155 & 1.158 & 1.155 & 1 & 1 & 1 \\
$I_{\text {fund }}[\mathrm{pu}]$ & 1.011 & 0.991 & 0.999 & 1.003 & 0.993 & 0.995 \\
$T H D_{I}[\%]$ & 8.327 & 10.801 & 8.417 & 4.840 & 4.365 & 4.868 \\
\hline \hline
\end{tabular}

\section{FEM VALIDATION}

In the previous Sections, two analytical models have been developed for a 6WT, based on a phasor approach (eq.s (1)(9)) and on a time domain Park approach (15), respectively.

The parameters have been identified by MS FEM simulations (both 2DRZ or 3D, Figures 3.a, 3.b), adopting a single column model.

Moreover, a particular procedure has been proposed to balance the SW current sharing, by changing the size $b_{2}$ (radial distance between the two central windings). Finally, the transformer performances under inverter supply have been 
analyzed by means of the proposed analytical model.

To verify both the analytical model and the current balancing procedure, a fully FEM approach has been adopted, using a 3D physical model of the three-phase 6WT (Fig. 5).

In these simulations, the PWs are supplied by suited voltage sources, equal to the reference values $\bar{V}_{P k}{ }^{*}$ obtained by (3), on the basis of (4) and (5), which allow equal PW currents, according to the proposed analytical model and to the proposed balancing procedure. The 3D FEM simulations have been performed both in terms of phasor FEM approach (where the sources are sinusoidal voltages, applied in terms of phasors $\bar{V}_{P k}{ }^{*}$ ) and in time domain (the sources are inverters where the amplitudes and phases of the control signals correspond to $\bar{V}_{P k} *$; inverter carrier signals are displaced by $120^{\circ}$ among them).

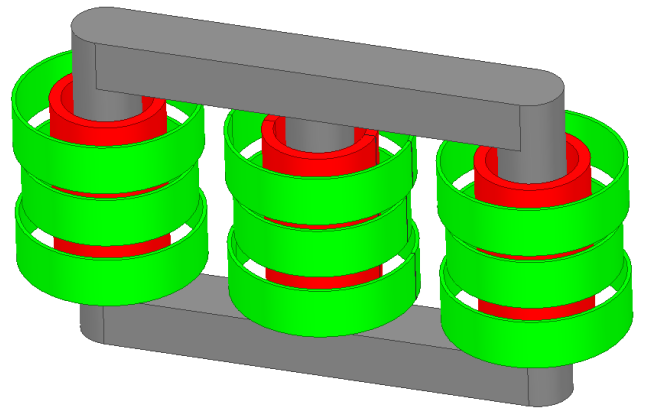

Fig. 5. 3D model of the $6 \mathrm{WT}$ of Table I, with $b_{1}=b_{3}=135 \mathrm{~mm}, b_{2}=107 \mathrm{~mm}$.

For a fair comparison with the analytical models, the FEM 3D simulations were firstly performed with linear magnetic material $\left(\mu_{\text {core }}=2000 \cdot \mu_{0}\right)$; then, a nonlinear silicon steel was adopted (JFE steel 50JN400).

Table IV reports the results of FEM 3D phasor analysis (Ansys Maxwell Eddy Currents tool [20], a solver in the phasor domain), under the hypothesis of $\mu_{\text {core }}=2000 \cdot \mu_{0}$.

The following remarks can be made:

- a fair agreement occurs among the pu currents for $b_{2 o p t}$ in Table II (analytical results from (7)), the fundamental pu currents of Table III (circuit numerical results from (15)) and the pu currents of Table IV (FEM 3D phasor analysis);

- referring to Table IV, a slight phase current unbalance can be seen in each limb winding, surely imputable to the core magnetic dissymmetry (different limb and yoke arrangements in central and external limbs), not taken into account by the analytical models.

A transient analysis, again under the hypothesis of $\mu_{\text {core }}=$ $2000 \cdot \mu_{0}$ has been performed by using a FEM 3D transient tool [20], interfacing a Schematic Editor, to suitably model the three feeding inverters with displaced carrier signals.

Fig. 6 shows the obtained transient waveforms.

The following remarks can be made:

- the waveforms in Fig. 6 show a fair balance, both in terms of current sharing and as concerns the three-phase behavior;

- both in the fundamental and in the ripple amplitudes, currents in Fig. 6 are very similar to the corresponding waveforms obtained by the transient model (15) (here not shown for lack of space); this validates the proposed model.

Finally, the FEM 3D simulations were performed also considering a non-linear, saturable core (JFE steel 50JN400).

Table $\mathrm{V}$ reports the results of the non-linear FEM 3D phasor analysis. Tables $\mathrm{V}$ values confirm the results of Table $\mathrm{IV}$, in terms of current sharing among 6WT windings: this is not surprising, because the current sharing depends on the leakage field in air, almost independent of core saturation; the latter affects the magnetizing current, usually low.
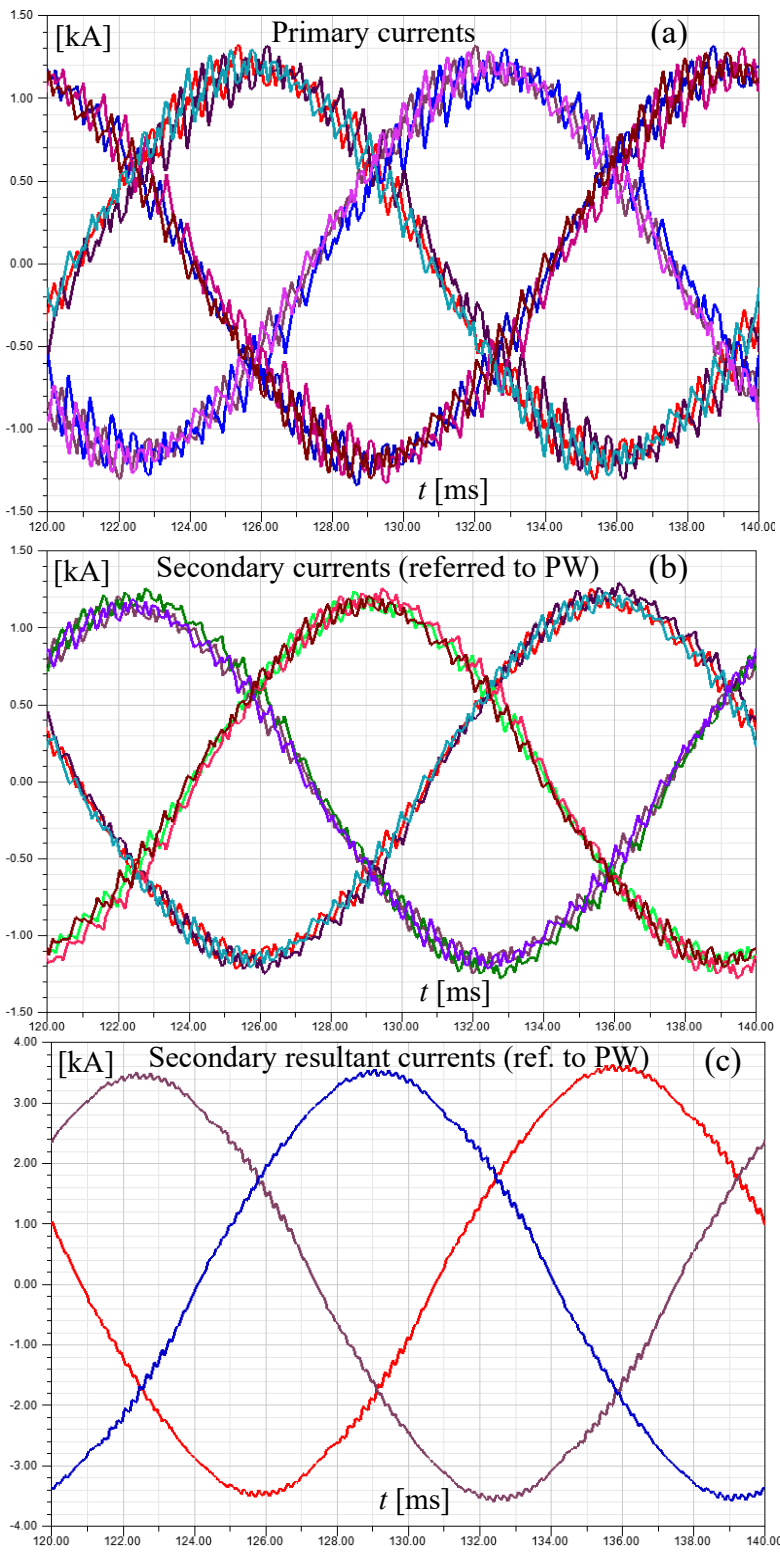

Fig. 6. 3D transient FEM simulation of the 6WT system, with un-saturable core $\left(\mu_{\text {core }}=2000 \cdot \mu_{0}\right): b_{1}=b_{3}=135 \mathrm{~mm}, b_{2}=b_{2 o p t}=107 \mathrm{~mm}$; inverter carrier signals displaced by $120^{\circ}$ among them: PW and SW currents waveforms at the terminals and resultant secondary current delivered to the mains (all secondary currents referred to PW side).

The FEM 3D transient simulation performed considering the non-linear material has shown waveforms very close to those in Fig.6; however, the simulations pointed out more critical convergence problems, due to the core non-linearity and to the needed accuracy in the field results, already cited as concerns the tight FEM simulation accuracy needed for the 
calculation of the inductance matrix.

The following concluding remarks can be made:

- these results, performed by FEM 3D simulations, both by phasor approach and by transient simulation, in linear and saturated conditions, show that the model developed in Sections III, IV is sound;

- referring to a $2 \mathrm{GHz}, 4$ core, $8 \mathrm{~GB}$ RAM PC, the time simulation based on (15) takes some tens of seconds; a FEM 3D simulation time with the AC 3D FEM solver lasts several hours; a transient 3D FEM analysis takes about two days for linear core, and more in case of saturable core.

TABLE IV

PU THREE-PHASE CURRENTS AT THE TERMINALS OF THE 6WT OF FIG. 5 $\left(b_{1}=b_{3}=135 \mathrm{~mm}, b_{2}=107 \mathrm{~mm}\right)$ CALCULATED BY A FEM 3D AC ANALYSIS (COMPLEX PHASOR FIELD SOlution: $f=50 \mathrm{~Hz}$ ); $\mu_{\text {core }}=2000 \cdot \mu_{0}$

\begin{tabular}{ccccccc}
\hline \hline $\begin{array}{c}\text { Winding } \\
\text { Column }\end{array}$ & $1 \mathrm{P}$ & $2 \mathrm{P}$ & $3 \mathrm{P}$ & $1 \mathrm{~S}$ & $2 \mathrm{~S}$ & $3 \mathrm{~S}$ \\
\hline$I_{A}[\mathrm{pu}]$ & 0.986 & 0.989 & 0.986 & 0.982 & 1.002 & 0.982 \\
$I_{B}[\mathrm{pu}]$ & 0.989 & 0.982 & 0.989 & 0.949 & 1.011 & 0.949 \\
$I_{C}[\mathrm{pu}]$ & 0.991 & 0.991 & 0.991 & 0.977 & 1.002 & 0.977 \\
\hline \hline
\end{tabular}

TABLE V

PU THREE-PHASE CURRENTS AT THE TERMINALS OF THE 6WT OF FIG. 5 $\left(b_{1}=b_{3}=135 \mathrm{~mm}, b_{2}=107 \mathrm{~mm}\right)$ : FEM 3D AC ANALYSIS (COMPLEX PHASOR FIELD SOLUTION: $f=50 \mathrm{~Hz}$ ); NON-LINEAR LAMIN.: JFE STEEL 50JN400

\begin{tabular}{lcccccc}
\hline \hline $\begin{array}{c}\text { Winding } \\
\text { Column }\end{array}$ & $1 \mathrm{P}$ & $2 \mathrm{P}$ & $3 \mathrm{P}$ & $1 \mathrm{~S}$ & $2 \mathrm{~S}$ & $3 \mathrm{~S}$ \\
\hline$I_{A}[\mathrm{pu}]$ & 0.984 & 0.988 & 0.984 & 0.985 & 1.001 & 0.984 \\
$I_{B}[\mathrm{pu}]$ & 0.988 & 0.981 & 0.987 & 0.952 & 1.009 & 0.952 \\
$I_{C}[\mathrm{pu}]$ & 0.986 & 0.989 & 0.986 & 0.983 & 1.001 & 0.982 \\
\hline \hline
\end{tabular}

\section{CONCLUSION}

A six-winding three-phase transformer has been proposed for the WECS-mains interface, with modular configuration, use of two-level inverters, significant redundancy features and suitable both in case of low and high de link voltage.

Some sizing guidelines have been defined and a transformer design example has been presented.

An analytical model of the 6WT has been developed.

The 6WT feeding and winding positioning conditions have been analyzed, to obtain a balanced current sharing.

The design parameter to be modified in order to obtain the secondary current balance is the distance $b_{2}$ between the two central windings: the procedure to obtain the optimal $b_{2}$ value is very simple (just two 2D MS FEM simulations).

Based on the analytical proposed model, some performances have been evaluated, with inverter supply.

Some 3D FEM simulations validated both the analytical model and the geometry-based current balancing procedure.

Further studies will concern the extension to a general number of modules and some experimental activity.

\section{REFERENCES}

[1] M.B. Wafaa, L-A. Dessaint: "Approach to dynamic voltage stability analysis for DFIG wind parks integration," IET Renewable Power Generation, Vol. 12, N. 2, 2018, pp. $190-197$.

[2] C. Ditmanson, P. Hein, S. Kolb, J. Mölck, S. Bernet: "A New Modular Flux-Switching PM Drive for Large Wind Turbines," IEEE Trans. on Ind. Appl., Vol. 50, N. 6, Nov./Dec. 2014, pp. 3787-3794.

[3] Y.-S. Park, M.-M. Koo, S.-M. Jang, J.-Y. Choi, D.-J. You: "Performance
Evaluation of Radial- and Axial-Flux PM Wind Power Generators With Mechanical Energy Storage System," IEEE Trans. on Energy Conversion, 2015, Vol. 30, N. 1, pp. $237-245$.

[4] O. Alizadeh, A. Yazdani: "A Control Strategy for Power Regulation in a Direct-Drive WECS With Flexible Drive-Train," IEEE Trans. on Sustainable Energy, 2014, Vol. 5, N. 4, pp. 1156-1165.

[5] D. Zhou, F. Blaabjerg: "Optimized Demagnetizing Control of DFIG Power Converter for Reduced Thermal Stress during Symmetrical Grid Fault," IEEE Tr. on Power Electr., 2018, V.33, N.12 pp. 10326-10340.

[6] E. Levi: "Multiphase Electric Machines for Variable-Speed Applications," IEEE Trans. on Ind. Electr., 2008, V.55, N.5, pp. 1893-1909.

[7] I. Gonzalez-Prieto, M. J. Duran, H.S. Che, E. Levi, M. Bermúdez, F. Barrero: "Fault-Tolerant Operation of Six-Phase Energy Conversion Systems With Parallel Machine-Side Converters," IEEE Trans on Power Electronics, 2016, Vol. 31, n. 4, pp. 3068 - 3079.

[8] T. Husain, I. Hasan; Y. Sozer; I. Husain; E. Muljadi: "Design of a Modular E-Core Flux Concentrating Transverse Flux Machine," IEEE Trans. on Industry Appl., 2018, Vol. 54, N. 3, pp. 2115 - 2128.

[9] V. Yaramasu, A.Dekka, M.J. Durán, S. Kouro, B. Wu, "PMSG-based wind energy conversion systems - survey on power converters and controls," IET Electric Power Appl., 2017,Vol. 11, No 6, pp. 956-968

[10] F. Blaabjerg, K. Ma, "Future on Power Electronics for Wind Turbine Systems," in IEEE Journal of Emerging and Selected Topics in Power Electronics, vol. 1, no. 3, pp. 139-152, Sept. 2013.

[11] S. Lundberg: "Evaluation of wind farm layouts," Eur. Power Electron. Drives Assoc. J., 2006, V. 16, N. 1, p. 14.

[12] A.Di Gerlando; K.ElShawarby; G.M.Foglia; R.Perini:"DC side current and torque ripples reduction in multi modular PMSG for wind applications," XXII Int. Conf. on Elec. Machines (ICEM), 2016, pp. 252-258.

[13] A. Di Gerlando; K. ElShawarby; M. Iacchetti, G. M. Foglia; R. Perini: "DC Current and Torque Ripple Mitigation in Modular PMSGs Drives for Multi-MW WECS with Linear PWM Inverter Modulation," XXIII Int. Conf. on Electrical Machines (ICEM), 2018, pp. 1458-1464.

[14] A. Di Gerlando; K. ElShawarby; G. M. Foglia, R. Perini: "Design and Modeling of Multi-Winding Transformers Interfacing Inverters and Mains," XXIII Int. Conf. on El. Machines (ICEM), 2018, pp. 656-662.

[15] L.Blume, A.Boyajian, G.Camilli, T.Lennox, S.Minneci, V.Montsinger: “Transformer Engineering," Wiley and Sons, 1951, pp. 122-129.

[16] D. J. Wilcox, M. Conlon and W. G. Hurley, "Calculation of self and mutual impedances for coils on ferromagnetic cores," in IEE Proc. A Science, vol. 135, no. 7, pp. 470-476, Sept. 1988.

[17] D.J. Wilcox, W.G. Hurley, M. Conlon, "Calculation of self and mutual impedances between sections of transformer windings," in IEE Proc. C, v. 136, no. 5, pp. 308-314, Sept. 1989.

[18] X. Margueron, J. Keradec, "Design of Equivalent Circuits and Characterization Strategy for n-Input Coupled Inductors," in IEEE Trans. on Ind. Appl., vol. 43, no. 1, pp. 14-22, Jan.-feb. 2007.

[19] C. Alvarez-Marino, F. de Leon, X. M. Lopez-Fernandez, "Equivalent Circuit for the Leakage Inductance of Multiwinding Transformers: Unification of Terminal and Duality Models," in IEEE Trans. on Power Delivery, vol. 27, no. 1, pp. 353-361, Jan. 2012.

[20] Ansys Electronics Desktop 2019 R1.

[21] PTC MathCad 15, 2010.

\section{BIOGRAPHIES}

Antonino Di Gerlando, senior member of IEEE, received his MS degree in electrical engineering from the Politecnico di Milano, Italy, in 1981. Currently, he is a Full Professor at the Dpt. of Energy at Politecnico di Milano. Fields of interest: design and modeling of electrical machines, converters and drive systems.

Khaled EIShawarby received his MS degree in electrical engineering in 2016 and the $\mathrm{PhD}$ degree in Electrical Engineering in 2019 at Politecnico di Milano, Italy. Currently, he is a Power Electronics Engineer at the Schlumberger Stonehouse Technology center, United Kingdom. His interests are in power electronics and electrical machines.

Giovanni Maria Foglia received his MS degree and the $\mathrm{PhD}$ in electrical engineering at Politecnico di Milano, Milano, Italy, in 1997 and 2000.

Currently, he is an Associate Professor at the Dpt. of Energy at Politecnico di Milano; main field of interest: analysis and design of PM electrical machines.

Roberto Perini (M'10) received his MS degree and the $\mathrm{PhD}$ in electrical engineering from the Politecnico di Milano, Milano, Italy. Currently, he is an Associate Professor at the Dpt of Energy at Politecnico di Milano. Main interests: design and modeling of electrical machines and power electronics. 